\title{
AVALIAÇÃO DA RESILIÊNCIA SOCIOECONÓMICA MUNICIPAL: PROCEDIMENTOS METODOLÓGICOS APLICADOS A PORTUGAL DURANTE A CRISE (2008-2013)
}

Carlos Gonçalves ${ }^{1}$

RESUMO - A magnitude e a recorrência dos episódios de crise desencadeados pós 2008, exigem novos referenciais para analisar os fatores e os contextos que (des)bloqueiam o progresso das comunidades. Avaliar a resiliência socioeconómica implica que se considerem as interações espaciais, temporais e setoriais conjugando os fatores que conferem persistência às trajetórias de desenvolvimento, com outros percussores de evolução e de transformação. Através da análise de 18 modelos que avaliam a resiliência territorial, desenvolvemos uma matriz de 22 indicadores organizada em 4 domínios (governança, estrutura urbana, económica e social), reproduzindo as dimensões socioeconómicas mais representativas. Quando aplicamos esta matriz aos municípios portugueses, considerando um período pré e outro pós início da crise de 2008, cartografamos um país vulnerável à crise e que perde potencial de desenvolvimento. A evolução entre pré e pós início da crise mostra o reforço da centralidade das áreas centrais e o aprofundamento da vulnerabilidade das periféricas.

Palavras-chave: Avaliação da resiliência; resiliência socioeconómica; domínios de resiliência; indicadores de resiliência; crise.

\begin{abstract}
MUNICIPAL SOCIOECONOMIC RESILIENCE ASSESSMENT: METHODOLOGICAL PROCEEDINGS APPLIED TO PORTUGAL DURING THE CRISIS (2008-2013). The magnitude and the recurrence of crisis episodes, which were triggered after 2008, demand a new set of references to allow us to analyse the factors and contexts that (un)block the progress of municipal communities. The assessment of socioeconomic resilience implies a thoughtful consideration of spatial, temporal and sectorial interactions, by combining factors that reinforce persistence to the development trajectories, along with other evolution and transformation drivers. A matrix of 22 indicators, organised in four
\end{abstract}

1 Bolseiro Pós-doc, Investigador Efetivo do Centro de Estudos Geográficos do Instituto de Geografia e Ordenamento do Território da Universidade de Lisboa, R. Branca Edmée Marques, 1600-276, Lisboa, Portugal. E-mail: c.goncalves@campus.ul.pt 
domains (governance and urban, economic and social structures), was developed through the analysis of 18 models which evaluate territorial resilience. This matrix replicates the most expressive socioeconomic dimensions. When applying it to Portuguese municipalities, considering that there were pre- and a post-crisis periods after the beginning of the 2008 crisis, we mapped a country that was vulnerable to crisis and, as a result, lost development potential. The evolution between the pre- and the post-crisis periods shows the strengthening of central areas and the intensification of the vulnerabilities in the peripheries.

Keywords: Resilience assessment; socio-economic resilience; resilience domains; resilience indicators; crisis.

RÉSUMÉ - ÉVALUATION DE LA RÉSILIENCE SOCIO-ÉCONOMIQUE DES MUNICIPALITÉS: UNE PROCÉDURE MÉTHODOLOGIQUE APPLIQUÉE À LA CRISE AU PORTUGAL (2008-2013). Tant l'ampleur que la récurrence des épisodes successifs de cette crise, exigent que des référentiels nouveaux soient appliqués à l'analyse des facteurs et des contextes qui ont bloqué, ou débloqué, le progrès des communautés territoriales. Pour évaluer leur résilience socio-économique, il faut considérer les interactions spatiales, temporelles et sectorielles, et il faut aussi conjuguer les facteurs assurant la persistance des trajectoires de développement, avec les autres causes d'évolution et de transformation. Lanalyse de 18 modèles évaluant la résilience territoriale, a permis de développer une matrice de 22 indicateurs, correspondant aux 4 domaines les plus importants (la gouvernance et les structures urbaine, économique et sociale). En appliquant cette matrice aux municipalités portugaises pendant les périodes pré- et post-début de la crise de 2008, on obtient l'image d'un pays vulnérable et qui perdait son potentiel de développement. On observe aussi que la centralité des zones centrales se renforçait et que la vulnérabilité des périphéries s’accroissait.

Mots clés: Evaluation de la résilience; résilience socio-économique; domaines de résilience; indicateurs de résilience; crise.

\section{RESILIÊNCIA NAS DINÂMICAS TERRITORIAIS}

Os estudos que recorrem à resiliência, enquanto referencial teórico, procuraram entender os processos que capacitam os sistemas (também os territoriais) para retomar a forma que assumiam antes de sofrerem os efeitos de um choque ou de uma crise. Durante a década de 1970 a investigação dedicada ao estudo dos ecossistemas, em paralelo com a que tem lugar no âmbito da psicologia, fizeram uso desta conceção de resiliência para estudar fenómenos naturais e comportamentos humanos. De seguida, as disciplinas relacionadas com a gestão de riscos e com o planeamento dedicado a resolver situações de emergência, manifestam interesse pelos determinantes da resiliência, embutindo-lhe a noção de robustez e de prevenção, viabilizando respostas proactivas a situações críticas (Chmutina, Lizarralde, Dainty, \& Bosher, 2016).

Tal como demonstram, primeiro Wilkinson (2012) depois Xu e Marinova (2013) e, mais recentemente, Meerow, Newell, e Stults (2016) e Pu e Qiu (2016) este esforço de reposicionar o racional a partir do qual se orientam os processos de desenvolvimento 
cresceu e propagou-se para outras disciplinas, chegando também à geografia humana à geografia económica e ao planeamento regional e urbano.

Quando discutidos nestes contextos disciplinares, os princípios maturados pela ecologia necessitaram de ser reavaliados e reposicionados, porque os sistemas socioeconómicos não são apartáveis do quadro de instituições, agentes, normas e convenções que os governam (Adger, 2000). Para tal, importa internalizar, por exemplo, conceitos de coesão e de equidade e relativizar outros de que são exemplos a adaptabilidade e a flexibilidade. De igual modo afigurou-se necessário responder a questões tais como: resiliência do quê? e, resiliência para quem? (Pendall, Foster, \& Cowell, 2009). Mas também, quando, onde e porquê (Meerow et al., 2016). Os autores citados, abordando a resiliência dos sistemas urbanos, sistematizam um conjunto de questões-chave, de entre as quais destacamos as seguintes: a que tipo de resiliência se deve dar prioridade?; a que tipos de perturbações devem os sistemas territoriais ser resilientes?; consideram-se as mudanças repentinas ou as que se manifestam de forma gradual?; considera-se a resiliência conjuntural (de curto prazo) ou estrutural (duradoura)?; coloca-se o foco nos benefícios para a geração presente ou para as futuras?; é possível determinar espaços ou setores prioritários?; quais os objetivos de fomentar resiliência?; o foco deve ser colocado no processo ou nos resultados? os reforços de resiliência numas regiões não suprime a de outras? (Meerow et al., 2016).

Todas as questões referidas convergem na abordagem espacial das dinâmicas territoriais. Importa equacionar os fatores que justificam o facto de, perante a mesma situação de crise, umas regiões regridem ou colapsam, enquanto outras resistem ou progridem. Para além disso, é necessário equacionar a hipótese de, ao reforçar a resiliência de uma região, ou como resposta a um evento de crise específico, se poder suprimir resiliência noutras regiões e/ou introduzir disfunções que a vulnerabilizam face a outros tipos de tensões (Foster, 2007). Também por isso é necessário equacionar modelos de governança pró-resiliência (Beilin \& Wilkinson, 2015).

Como reflexo da incorporação do referencial da resiliência nas discussões sobre os desafios colocados ao desenvolvimento, o interesse pela aplicação deste quadro conceptual convoca formulações que potenciem aplicabilidade. Esta frente de discussão teórica e de aplicação prática ganha relevo com a sucessão de crises desencadeadas pós 2008, conduzindo a que se questione se não estaremos perante um período (prolongado) de fracassos sincronizados. Se é certo que no passado também existiram crises, também é necessário admitir que a rotura marcada pela crise financeira de 2008 desencadeou um padrão sem precedentes, pelo seu carater sistémico e intersistémico manifestado quer nas causas quer nas consequências (Homer-Dixon et al., 2015).

Procurando responder aos reptos impostos pelo aprofundamento do contexto de crise, a geografia económica adaptou este quadro conceptual, procurando afastá-lo dos princípios de equilíbrio e aproximando-o dos de evolução que é assegurada por mecanismos de adaptabilidade de longo prazo. Esta exigência implica compaginar a capacidade dos sistemas territoriais para, no curto prazo, absorver choques e desencadear novas trajetórias de desenvolvimento duradouras, perceber melhor como se originam e reforçam esses tipos de trajetórias, manter uma negociação permanente entre os objetivos da adaptabilidade e os da adaptação e incorporar a natureza complexa e multidimensional 
da resiliência socioeconómica. Perspetivada pela lente evolutiva, a resiliência de uma região joga-se na interação entre adaptação e adaptabilidade. A primeira implica ganhos incrementais no lastro de recursos do passado, a segunda exige que se criem condições para lhe introduzir mudanças sempre que tal for necessário (Boschma, 2014).

Meerow et al. (2016, p. 45), sintetizam um conjunto de definições centradas nos sistemas urbanos, propondo uma formulação agregadora:

“(...) urban resilience refers to the ability of an urban system and all its constituent socio-ecological and socio-technical networks across temporal and spatial scales to maintain or rapidly return to desired functions in the face of a disturbance, to adapt to change, and to quickly transform systems that limit current or future adaptive capacity."

O papel da geografia na incorporação da lente evolutiva contribui para que o conceito se orientasse para os fatores de transformação, questionando a lógica de equilíbrio, assumindo que os territórios mudam com (ou sem) influência de fatores externos. Esta abordagem traz consigo uma mudança de paradigma na interpretação dos processos de desenvolvimento e dos episódios de tensão e de crise, procurando explicações para além da ordem e da previsibilidade mecânica, recorrendo a princípios de complexidade, de caos, de incerteza e de descontinuidade, perspetivando fatores que desencadeiam mudanças, adaptações e transformações civilizacionais profícuas (Martin \& Sunley, 2003; Boschma \& Martin, 2007; Simmie \& Martin, 2010; Davoudi, 2012).

Resiliência territorial incorpora interações espaciais, temporais e setoriais dinâmicas, atendendo em simultâneo às tensões decorrentes de trajetórias de persistência, de transição e de transformação. Privilegia processos de adaptação estrutural preterindo adaptabilidade pontual e específica, requer negociação permanente para que se determinem, em cada caso, a importância de fatores de adaptação, de transição, de incremento e de transformação. O referencial teórico da resiliência, depois de absorver os incrementos da discussão tida nas disciplinas que se ocupam dos motores e dos bloqueios que catapultam ou que travam a evolução das sociedades, permite refletir sobre o presente, sobretudo em contextos de crescente incerteza, discutir o futuro e escolher, entre um quadro de intervenções, as que garantem ganhos civilizacionais mais duradouros.

Teigão dos Santos e Partidário (2011) apresentam a resiliência como um pré-requisito para a sustentabilidade porque assegura e amplia o número de opções de desenvolvimento, potenciando capacidade de gerir, adaptar e transformar perante a necessidade de mudança. Para estes autores a resiliência é vista como uma alternativa à resignação, obrigando a enquadrar as dinâmicas dos sistemas socioeconómicos no quadro do pensamento sistémico, a considerar contextos de complexidade, cenários de incerteza, de perturbações, bem como, a existência de limiares de funcionamento. Requer que se posicionem as trajetórias de desenvolvimento na arquitetura do ciclo adaptativo, não negligenciando as interdependências que se estabelecem entre várias escalas nem o reforço da capacidade de adaptação, antevendo e ultrapassando vulnerabilidades. A matriz de princípios de resiliência sintetizados por Teigão dos Santos e Partidário (2011) implica que se transformem processos e mentalidades no sentido de substituir o paradigma de "comando/controle" pelo de "aprender/adaptar". 
Autores como Cachinho (2012) e Fernandes e Chamusca (2012) discutem e aplicam o conceito de resiliência no âmbito da vitalidade e da sustentabilidade dos sistemas urbano-comerciais, atendendo à capacidade de adaptação que incorporam e também à influência das políticas públicas que geram maior ou menor resiliência.

Avaliar a resiliência socioeconómica é um objetivo partilhado pelos autores que trabalham neste campo de investigação (citamos apenas cinco exemplos recentes: Giannakis \& Bruggeman, 2015; Sensier, Bristow, Healy, \& Kiel, 2016; Martin, 2016; Hung, Yang, Chien, \& Liu, 2016; Suárez, Gómez-Baggethun, Benayas, \& Tilbury, 2016). Contudo os modelos disponíveis são ainda escassos. A imprevisibilidade provocada pela recorrência de crises de diferentes tipos (ambientais, económicas, sociais, políticas) confere crescente importância à necessidade de se poder avaliar a robustez da evolução dos sistemas socioeconómicos, sem esquecer a importância que nestes desempenha o domínio da governança.

Esta súmula de perspetivas conduz a que se considere um território resiliente quando incorpora competências para estabelecer ou, sempre que for necessário, restabelecer resultados favoráveis ao longo do tempo (não obstante, os episódios de crise) desencadeando ininterruptamente mudanças socioeconómicas profícuas, visíveis na capacidade de manter ou recuperar trajetórias de progresso nos quadros de vida quotidianos. Avaliar a resiliência territorial face a perturbações ou crises implica uma abordagem sistémica que concilie efeitos nas estruturas sociais, económicas, urbanas e de governança que permitam posicionar a multidimensionalidade das dinâmicas territoriais antes e depois dos episódios disruptivos.

Nas secções seguintes desenvolve-se um modelo para avaliar a resiliência socioeconómica municipal face a crises dessa natureza que depois se aplica aos municípios portugueses, avaliando os primeiros efeitos da crise pós 2008. Para tal, selecionamos um conjunto de domínios e de atributos associados à resiliência socioeconómica verificando a recorrência com que são usados em estudos onde se desenvolvem modelos de avaliação. De seguida, registamos os indicadores usados para medir resiliência ou vulnerabilidade nos domínios ambiental, social, económico e da governança.

A capacidade adaptativa foi avaliada através de variáveis, tais como, padrões de consumo, níveis de educação, diversificação do rendimento ou robustez institucional. De igual forma, o domínio governança, também foi conjugado com os restantes. Assim, avaliamos a resiliência socioeconómica municipal através da confluência entre domínios sociais, económicos, processo de urbanização e governança.

Em síntese, o artigo estrutura-se da seguinte forma: i) propõe-se um percurso metodológico para avaliar a resiliência socioeconómica municipal identificando um quadro de domínios e indicadores, procedendo à sua calibração e formulando uma tipologia de capacidade de resiliência; ii) aplica-se esta metodologia para avaliar os efeitos da crise pós-2008 na resiliência socioeconómica dos municípios de Portugal Continental posicionando a dinâmica dos 278 municípios nas 6 classes da tipologia encontradas; iii) discutem-se os resultados observando a distribuição dos municípios de acordo com o índice de resiliência e vulnerabilidade antes da crise $\left(\mathrm{t}_{1}\right)$, no decurso da primeira fase da crise $\left(t_{2}\right)$ e atendendo à tipologia de evolução (variação entre $t_{1}$ e $t_{2}$ ). 


\section{METODOLOGIA PARA AVALIAR A RESILIÊNCIA SOCIOECONÓMICA MUNICIPAL}

\section{Domínios e indicadores de resiliência socioeconómica}

Para o processo de seleção dos domínios e dos indicadores neles incluídos selecionam-se 18 casos de estudo. Esses 18 exemplos foram escolhidos por 3 razões: i) os autores detalham os modelos desenvolvidos, ii) permitem diferenciar os respetivos domínios e indicadores usados na avaliação e, iii) direcionam (total ou parcialmente) a avaliação para domínios socioeconómicos.

Primeiramente identificaram-se, nos modelos analisados, os domínios em que se organizam as propostas de avaliação da resiliência. Constatamos que o número de domínios e de especificidades temáticas não se apresentam de forma uniforme. De modo a suprimir as discrepâncias classificaram-se todas as designações por referência a cinco domínios de avaliação: ambiental; social; económico, estrutura urbana; e, governança.

Os 18 estudos analisados organizam a informação em 99 domínios. Das 103 entradas identificadas como domínios, é notória a preponderância dos indicadores "económicos" e "sociais", correspondendo a 38,8\% (40 registos de domínios coincidentes) e 30,1\% (31 registos) respetivamente. Nesta cadeia de primazia, o domínio "estrutura urbana" corresponde a $18,4 \%$ dos registos e o da "governança" a 8,7\%.

Esta amostra composta por 18 casos de estudo traduz a importância dada a cada domínio nestes modelos de avaliação. Num primeiro plano as questões sociais e económicas, depois as relacionadas com a estruturação dos espaços urbanos e por fim, as de governança. Quando se observa o total de indicadores usados nestes estudos organizados numa grelha de domínios, a sua importância relativa sofre algumas deformações. Registamos o uso de 438 indicadores nos 18 estudos analisados, 32,9\% (144 indicadores) relacionam-se com aspetos económicos, 28,1\% (123 indicadores) correspondem a informação do domínio social, 25,3\% (111 indicadores) reportam elementos definidores da estrutura urbana e 11,4\% (50 indicadores) trazem para os modelos os aspetos da governança (quadro I). Sublinha-se o facto de os domínios da "estrutura urbana" e da "governança", não sendo preponderantes, estarem representados em quase todos os modelos, o que leva a que a sua expressão na representação dentro dos indicadores seja mais significativa do que na dos domínios.

Quando se identificam os domínios prevalecentes (quadro I), tomando em linha de conta os que registam o maior valor de indicadores em cada estudo, a representação dos que ocupam o campo económico é bastante mais expressiva. Os indicadores dedicados a internalizar este tipo de questões são prevalecentes em 10 dos 18 estudos. Os indicadores sociais são maioritários em 4 , os da estrutura urbana em 3 e os da governança em 2. A representação dos domínios na amostra de estudos analisada, não sendo exaustiva, mostra-se adequada, considerando-se que a continuação da recolha resultaria, sobretudo, na consolidação de redundâncias. 
Quadro I - Distribuição, por domínios, dos indicadores recolhidos nos modelos analisados.

Table I - Distribution, by domains, of the indicators collected in the analysed models.

\begin{tabular}{|c|c|c|c|c|c|c|}
\hline \multirow[b]{2}{*}{ Fontes bibliográficas analisadas } & \multirow{2}{*}{$\begin{array}{c}\text { No de } \\
\text { indicadores }\end{array}$} & \multicolumn{5}{|c|}{ Distribuição do número de indicadores por domínios } \\
\hline & & Ambiente & Social & Economia & $\begin{array}{c}\text { Estrutura } \\
\text { Urbana }\end{array}$ & Governança \\
\hline Wolman, Ford, \& Hill (1994) & 5 & 0 & 1 & 4 & 0 & 0 \\
\hline Cutter, Boruff, \& Shirley (2003) & 11 & 0 & 5 & 4 & 2 & 0 \\
\hline Foster (2006) & 7 & 0 & 1 & 5 & 1 & 0 \\
\hline Cutter et al. (2008) & 17 & 0 & 8 & 4 & 5 & 0 \\
\hline Pinho et al. (2008) (Capítulo 2) & 70 & 1 & 33 & 10 & 25 & 1 \\
\hline Pinho et al. (2008) (Capítulo 11) & 44 & 4 & 10 & 1 & 25 & 4 \\
\hline Briguglio, Cordina, Farrugia, \& Vella (2009) & 14 & 0 & 3 & 3 & 0 & 8 \\
\hline Naudé, McGillivray, \& Rossouw (2009) & 21 & 3 & 4 & 10 & 3 & 1 \\
\hline $\begin{array}{l}\text { European Commission Directorate-General for } \\
\text { Economic and Financial Affairs (2009) }\end{array}$ & 4 & 0 & 0 & 4 & 0 & 0 \\
\hline Wolleb \& Daraio (2009) & 4 & 0 & 1 & 3 & 0 & 0 \\
\hline Cutter, Burton, \& Emrich (2010) & 36 & 0 & 11 & 6 & 8 & 11 \\
\hline Sousa (2010) & 53 & 0 & 19 & 14 & 20 & 0 \\
\hline Chapple \& Lesterb (2010) & 29 & 0 & 10 & 15 & 2 & 2 \\
\hline Barata Salgueiro (2011) & 45 & 0 & 4 & 11 & 16 & 14 \\
\hline Martin (2012) & 9 & 0 & 0 & 9 & 0 & 0 \\
\hline Ferrão (2012) & 16 & 0 & 3 & 13 & 0 & 0 \\
\hline ESPON (2013) & 37 & 2 & 6 & 19 & 3 & 7 \\
\hline http://brr.berkeley.edu/rci//* & 16 & 0 & 4 & 9 & 1 & 2 \\
\hline Total & 438 & 10 & 123 & 144 & 111 & 50 \\
\hline$\%$ & & 2,3 & 28,1 & 32,9 & 25,3 & 11,4 \\
\hline Domínios prevalecentes & & 0 & 4 & 10 & 3 & 2 \\
\hline
\end{tabular}

* A informação sobre a distribuição dos indicadores por domínios, incluídos no Resilience Capacity Index e sobre a metodologia de cálculo que o suporta, foi consultada através da plataforma online http://brr.berkeley.edu/rci/ (acedida em 2 de maio de 2013). Esta plataforma integrava o projeto Building Resilient Regions do Instritute of Governmental Studies da University of California - Berkeley. A investigação em causa, congregava um grupo de investigadores coordenados por Kathryn Kathryn Foster (Investigadora Principal da MacArthur Foundation Research Network on Building Resilient Regions e directora da University at Buffalo Regional Institute).

\section{Calibração da matriz de indicadores}

Para orientar a seleção de indicadores primeiramente classificaram-se os domínios por temas de modo a atender a dois objetivos: por um lado, determinar os temas mais visados e, por outro, ter uma ordem de grandeza sobre os mais recorrentes. Isto é, quais os temas abordados em cada componente e quais são os usados com mais frequência. Nesta etapa trabalhamos sobre uma lista de 428 indicadores divididos, agora, por 4 domínios (fig. 1).

Com este exercício, acede-se aos tipos de indicadores utilizados nos modelos de avaliação da resiliência. Deste modo podemos ajustar, respeitando a proporcionalidade verificada, o modelo aqui proposto com os domínios e indicadores mais usados nos estudos que tomamos como referência. Isso reflete-se no número, na repartição pelos diferentes domínios e na natureza dos indicadores que integram a matriz de avaliação da resiliência socioeconómica municipal. 


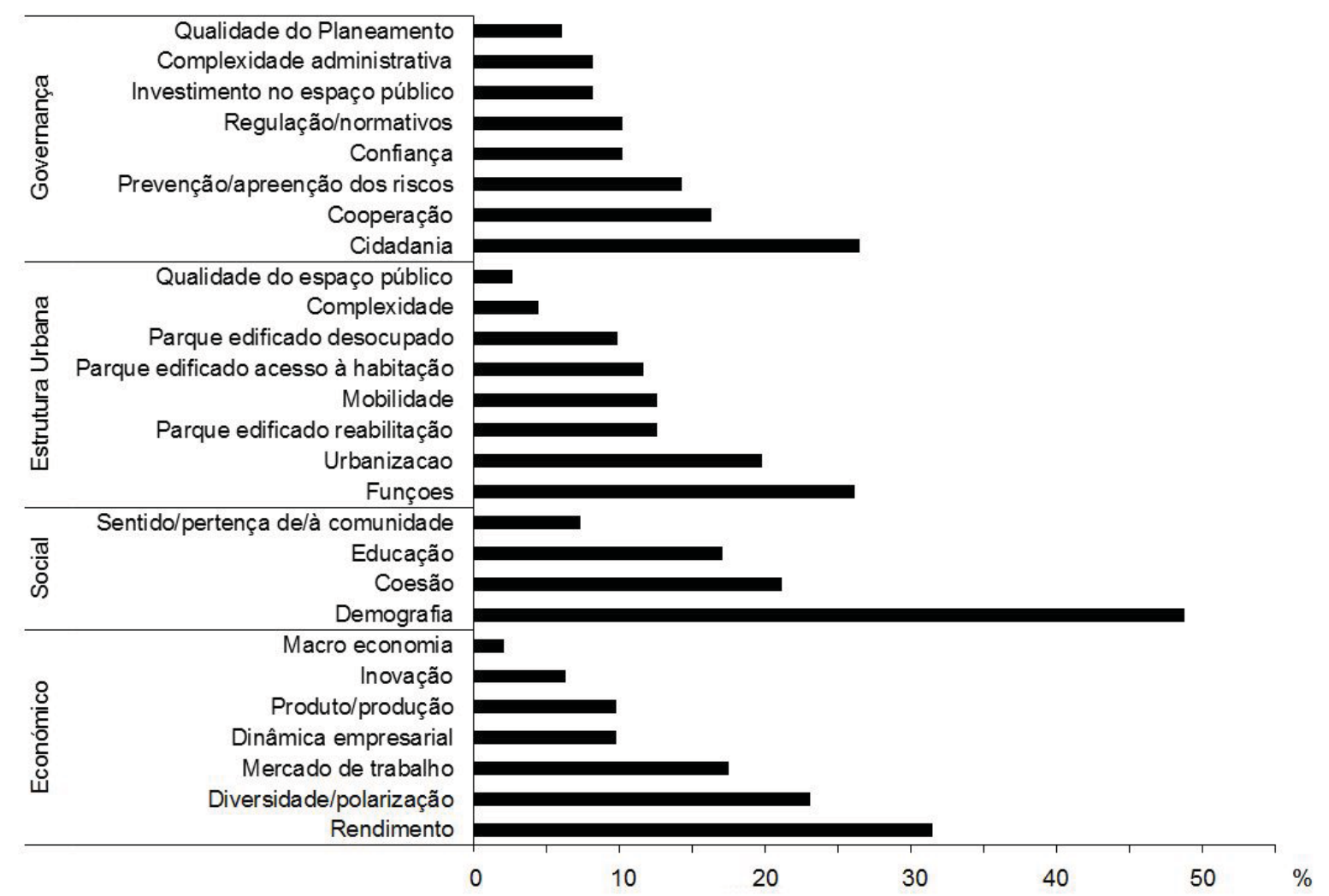

Fig. 1 - Tipologia dos indicadores de resiliência (por domínio) extraídos dos 18 estudos selecionados.

Fig. 1 - Typology of resilience indicators (by domain) extracted from the 18 selected studies.

Na etapa seguinte confrontam-se as orientações do exercício de recolha e catalogação dos indicadores mais usados nos modelos com a informação disponível nas fontes de informação estatística. Para o efeito recorremos exclusivamente a fontes estatísticas oficiais: os anuários estatísticos regionais entre 1999 e 2011 e Censos da população 2001 e 2011, ambos disponibilizados pelo Instituto Nacional de Estatística (INE).

Os objetivos que orientaram a verificação das fontes de informação foram: i) aproximar os indicadores selecionados (o mais possível) dos fundamentos inerentes aos domínios, aos atributos e à preponderância dos indicadores sinalizada anteriormente; ii) poder encontrar indicadores preferencialmente para os anos de 2001 e 2011 (quando tal não fosse possível, no mínimo, teriam de apresentar informação para um ano anterior a $2007 / 2008$ e outro posterior a estes), repercutindo o estado pré-crise $\left(t_{1}\right)$ e o sentido e magnitude da performance até um momento pós-crise $\left(\mathrm{t}_{2}\right)$; iii) possibilitar que esses indicadores reproduzissem informação à escala do município na medida em que é aquela onde se maximiza o compromisso entre a quantidade e diversidade de informação disponível e a proximidade à escala de funcionamento quotidiano das comunidades. Se a escala regional aumentava a disponibilidade de informação também afastava os resultados dos contextos territoriais onde se verificam os efeitos mais diretos da crise na vida das pessoas, das famílias e das comunidades. Por outro lado, para as escalas mais próximas das comunidades (freguesias, lugares, secções, subsecções) a informação disponível é menor. Deste exercício de conciliação resultou uma matriz de 22 indicadores (quadro II) cobrindo (preferencialmente) o intervalo temporal entre 2001 e 2013. 
Quadro II - Modelo de Avaliação da Resiliência Socioeconómica Municipal.

Table II - Municipal Socioeconomic Resilience Assessment Model.

\begin{tabular}{|c|c|c|c|c|c|c|}
\hline \multirow[t]{2}{*}{ 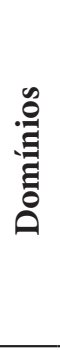 } & \multirow[t]{2}{*}{ 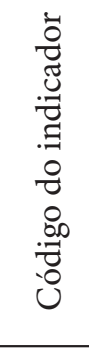 } & & & & & \multirow[t]{2}{*}{ 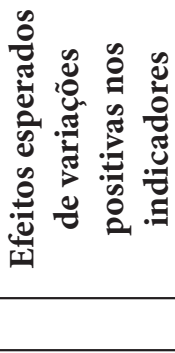 } \\
\hline & & Indicadores & Unidade & $\mathbf{t}_{1}$ & $\mathbf{t}_{2}$ & \\
\hline \multirow{10}{*}{. } & s1 & Índice de dependência total & $\%$ & 2007 & 2012 & $\downarrow$ \\
\hline & s2 & Proporção de famílias clássicas unipessoais & $\%$ & 2001 & 2011 & $\downarrow$ \\
\hline & s3 & Beneficiários do rendimento social de inserção & $\%$ & 2007 & 2012 & $\downarrow$ \\
\hline & s4 & $\begin{array}{l}\text { Proporção da população residente de nacionalidade } \\
\text { estrangeira }\end{array}$ & $\%$ & 2001 & 2011 & $\uparrow$ \\
\hline & s5 & Taxa de variação da população residente & $\%$ & $1991 / 2001$ & $2001 / 2011$ & $\uparrow$ \\
\hline & s6 & Médicas/os por 1000 habitantes & $\%$ & 2007 & 2012 & $\uparrow$ \\
\hline & s7 & $\begin{array}{l}\text { Proporção da população residente com ensino } \\
\text { superior completo }\end{array}$ & $\%$ & 2001 & 2011 & $\uparrow$ \\
\hline & s8 & $\begin{array}{l}\text { Disparidade no ganho médio mensal entre } \\
\text { profissões }\end{array}$ & $\%$ & 2007 & 2011 & $\downarrow$ \\
\hline & s9 & $\begin{array}{l}\text { Levantamentos nacionais em caixas multibanco } \\
\text { por habitante }\end{array}$ & $€$ & 2007 & 2012 & $\uparrow$ \\
\hline & s10 & $\begin{array}{l}\text { Encargos médios mensais por aquisição de } \\
\text { habitação própria }\end{array}$ & $€$ & 2001 & 2011 & $\downarrow$ \\
\hline \multirow{5}{*}{ 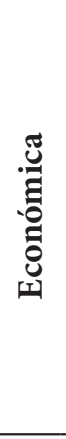 } & e11 & $\begin{array}{l}\text { Proporção de pessoal ao serviço das empresas na } \\
\text { construção, comércio por grosso e retalho e } \\
\text { reparação de veículos automóveis }\end{array}$ & $\%$ & 2007 & 2011 & $\downarrow$ \\
\hline & e12 & $\begin{array}{l}\text { Indicador de concentração do volume de negócios } \\
\text { das } 4 \text { maiores empresas }\end{array}$ & $\%$ & 2007 & 2011 & $\downarrow$ \\
\hline & e13 & $\begin{array}{l}\text { Taxa de variação do total de pessoal ao serviço das } \\
\text { empresas }\end{array}$ & $\%$ & $2005 / 2008$ & $08 / 2011$ & $\uparrow$ \\
\hline & e14 & Proporção das empresas da divisão M (CAE REV.3) & $\%$ & 2007 & 2012 & $\uparrow$ \\
\hline & e15 & Taxa de desemprego & $\%$ & $01 / 2008$ & $01 / 2013$ & $\downarrow$ \\
\hline \multirow{5}{*}{ 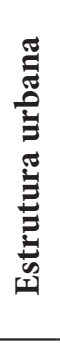 } & eu16 & $\begin{array}{l}\text { Proporção de população residente em lugares com } \\
2000 \text { ou mais habitantes }\end{array}$ & $\%$ & 2001 & 2011 & $\uparrow$ \\
\hline & eu17 & Densidade populacional & $\mathrm{hab} / \mathrm{km}^{2}$ & 2001 & 2011 & $\uparrow$ \\
\hline & eu18 & $\begin{array}{l}\text { Média de reconstruções concluídas por } 100 \\
\text { construções novas concluídas }\end{array}$ & $\%$ & $2003 / 2007$ & $2008 / 2012$ & $\uparrow$ \\
\hline & eu19 & Duração média dos movimentos pendulares & $\min$ & 2001 & 2011 & $\downarrow$ \\
\hline & eu20 & Taxa de atracção total & $\%$ & 2001 & 2011 & $\uparrow$ \\
\hline \multirow{2}{*}{ 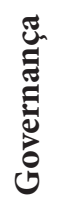 } & g21 & $\begin{array}{l}\text { Taxa de abstenção nas eleições para as Câmaras } \\
\text { Municipais }\end{array}$ & $\%$ & 2005 & 2013 & $\downarrow$ \\
\hline & g22 & $\begin{array}{l}\text { Proporção das actividades de organizações } \\
\text { associativas }\end{array}$ & $\%$ оо & 2007 & 2011 & $\uparrow$ \\
\hline
\end{tabular}

Da quantificação de 22 indicadores (10 no domínio social, 5 no económico, 5 na estrutura urbana e 2 no da governança) obtêm-se quatro índices: índice de resiliência 
social; índice de resiliência económica; índice de resiliência da estrutura urbana; e, o índice de resiliência da governança. Da conjugação dos 4 índices resulta um índice agregado de avaliação da resiliência socioeconómica municipal.

\section{Tipologia de capacidade de resiliência}

O percurso metodológico resume-se na execução das operações que de seguida se descrevem. Recolheram-se os dados para os diferentes indicadores, pesquisando nas fontes indicadas e procedeu-se à sua normalização, nas colunas constam os valores correspondentes às observações em $t_{1}$ e em $t_{2}$ (quadro II). Com base nestas observações, procedeu-se ao calculado dos $z$-sores para todos os indicadores (para $t_{1}$ e para $t_{2}$ ), seguindo

a fórmula: $z=\frac{x-\mu}{\sigma}$; em que $x$ corresponde ao valor registado na unidade de análise $\mathrm{x}$, $\mu$ corresponde ao valor registado para Portugal Continental e $\sigma$ ao desvio padrão. O valor do Continente substituiu a média, uma vez que os termos que entram no cálculo da média, não coincidem com os que são considerados para aferir a posição de Portugal Continental nos diferentes indicadores. Tomando como exemplo o caso da taxa de variação da população entre 1991 e 2001 o valor registado foi de 5,2\%. Se se considerar a média dos 278 concelhos o valor seria $0,8 \%$. Como o objetivo é aferir a posição relativa de cada concelho (em desvios padrão) face à performance de Portugal Continental no seu todo, a opção recaiu na ponderação pelo valor apresentado para essa escala. No caso do indicador e12 o cálculo foi feito tendo em conta a média dos valores registados nos 278 concelhos.

Selecionaram-se todos os casos em que o indicador, sendo elevado, corresponderia a um desgaste na capacidade de resiliência procedendo-se à inversão de sinal, multiplicando os respectivos valores por -1. Nesta situação estão os indicadores s1, s2, s3, s8, s10, e11, e12, e15, eu19, g21, por registarem perdas de resiliência tanto maiores quando mais elevados forem os valores dos $z$-scores e vice-versa. Deste modo normalizaram-se os resultados por referência ao racional "quanto mais elevado o valor mais contribui para a resiliência", e "quanto menos elevado o valor, mais acrescenta à vulnerabilidade" do município em causa.

Para gerar a tipologia em seis classes que posiciona cada indicador por referência ao gradiente de resiliência representado à direita na figura 2, desencadearam-se outros exercícios. Para além do cálculo dos totais agregando os resultados nos 22 indicadores, organizamos os respetivos municípios em rankings para $t_{1}$ e para $t_{2}$ calculando-se a evolução entre ambos. A figura 2 esquematiza esta operação que obedeceu ao seguinte racional:

- trajetória A.i - os concelhos com valores de $z$-scores superiores a 0 em $\mathrm{t}_{1}$ e em $\mathrm{t}_{2}$, registando cumulativamente subidas no ranking entre $t_{1} e t_{2}$, capitalizaram a sua resiliência relativa, por referência ao sucedido no cômputo de Portugal Continental (classificando-se com 3);

- trajetória A.ii - os concelhos com valores de $z$-scores superiores a 0 em $t_{1}$ e em $t_{2}$, registando cumulativamente descidas no ranking entre $t_{1}$ e $t_{2}$, reduziram a sua capacidade de resiliência relativa (classificando-se com 2); 
- trajetória A.iii - os concelhos com valores de $z$-scores superiores a 0 em $t_{1}$ e inferiores a $0 \mathrm{em} t_{2}$ registando cumulativamente descidas no ranking entre $t_{1}$ e $t_{2}$, tornaram-se vulneráveis (classificando-se com -1);

- trajetória B.iv - os concelhos com valores de $z$-scores inferiores a 0 em $t_{1}$ e superiores a 0 em $t_{2}$ registando cumulativamente subidas no ranking entre $t_{1}$ e $t_{2}$, tornaram-se resilientes (classificando-se com 1);

- trajetória B.v - os concelhos com valores de $z$-scores inferiores a 0 em $t_{1}$ e em $t_{2}$ mas que registaram cumulativamente subidas no ranking entre $t_{1}$ e $t_{2}$, reduziram vulnerabilidade relativa (classificando-se com -2);

- trajetória B.vi - os concelhos com valores de $z$-scores inferiores a 0 em $\mathrm{t}_{1}$ e em $\mathrm{t}_{2} \mathrm{e}$ que registaram cumulativamente descidas no ranking entre $t_{1}$ e $t_{2}$, capitalizaram vulnerabilidade relativa (classificando-se com -3).

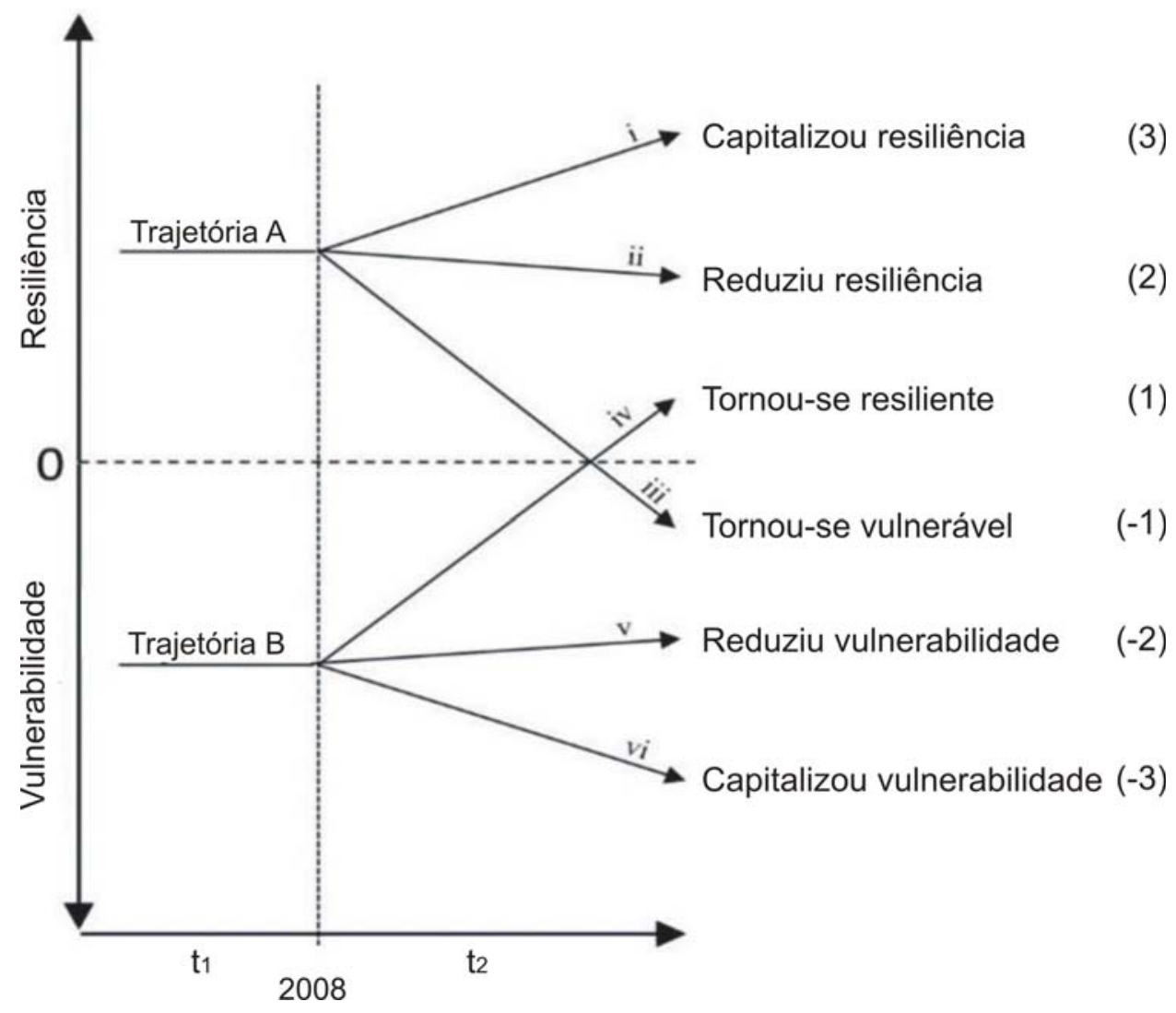

Fig. 2 - Tipologia de capacidade de resiliência em 6 trajetórias.

Fig. 2 - Typology of resilience capacity in 6 classes.

Desta matriz de avaliação resulta uma miríade de possibilidades de análise e de representação dos resultados: desde o tratamento isolado para cada indicador, à observação conjunta para cada componente, até à verificação das indicações fornecidas pelo índice agregado. Podemos representar e analisar os resultados tendo em conta a sua evolução entre $t_{1}$ e $t_{2}$, os posicionamentos das unidades de análise nos rankings para os dois períodos, o reposicionamento dos municípios nesses rankings ou a sua posição na tipologia apresentada. 


\section{EFEITOS DA CRISE PÓS-2008 NA RESILIÊNCIA SOCIOECONÓMICA MUNICIPAL}

A avaliação da resiliência e da vulnerabilidade das estruturas socioeconómicas em Portugal Continental ganha maior expressão quando se consideram os resultados agregados dos 22 indicadores, incluídos no quadro II, transpondo-se para uma única medida a evolução nas componentes sociais, económica, da estrutura urbana e da governança.

A distribuição dos 278 municípios pelas diferentes classes, atendendo à sua posição pré $\left(\mathrm{t}_{1}\right)$ e pós-crise $\left(\mathrm{t}_{2}\right)$ consta no quadro III.

Em $t_{1}$ registam-se 185 municípios $(65,5 \%)$ posicionados nas classes que denunciam vulnerabilidade. Por aqui se percebe que a estrutura que sofre os impactos da crise é na maior parte dos casos, frágil. Esta representação subiu para 81,6\% (227) no período de transição para $t_{2}$. Decorre daqui a transferência de 42 concelhos das classes de maior resiliência para as que denotam situações de vulnerabilidade. Ou seja, as conclusões apontam para um crescimento da vulnerabilidade, atentando ao número de municípios que demonstram esses resultados (cerca de 23\%). Apenas 51 municípios (18,4\%) apresentam estruturas socioeconómicas onde a capacidade de dar continuidade ao processo de desenvolvimento estava menos comprometida, por referência ao contexto geral de crise despoletada em 2008.

Essa situação de agravamento é mais evidente pela análise das tipologias que reportam à evolução ocorrida entre os dois períodos considerados. Ganhos relativos de resiliência foram registados em 31 municípios $(11,2 \%)$, ao passo que os que aprofundaram situações de vulnerabilidade totalizam 88 (31,7\%).

Quadro III - Distribuição dos municípios de acordo com o índice de resiliência e vulnerabilidade antes $\left(\mathrm{t}_{1}\right)$, no decurso da crise $\left(\mathrm{t}_{2}\right)$ e tipologia de evolução (6 classes).

Table III - Distribution of municipalities according to the index of resilience and vulnerability before the crisis $\left(t_{1}\right)$, during of the crisis ( $\left.t_{2}\right)$ and typology of evolution ( 6 classes).

\begin{tabular}{|c|c|c|c|c|c|c|c|}
\hline \multirow{2}{*}{ Classes } & \multicolumn{2}{|c|}{$t_{1}$} & \multicolumn{2}{|c|}{$t_{2}$} & \multicolumn{3}{|c|}{ Tipologia de evolução em 6 classes } \\
\hline & $\mathrm{n}^{\mathbf{o}}$ & $\%$ & $\mathrm{n}^{\mathbf{o}}$ & $\%$ & & $\mathbf{n}^{\mathbf{o}}$ & $\%$ \\
\hline 16 a 24 & 4 & 1,4 & 1 & 0,4 & Capitalizou resiliência (3) & 31 & 11,2 \\
\hline 8 a 16 & 12 & 4,3 & 7 & 2,5 & Reduziu resiliência (2) & 18 & 6,5 \\
\hline 0 a 8 & 77 & 27,7 & 43 & 15,5 & Tornou-se resiliente (1) & 2 & 0,7 \\
\hline Total parcial & 93 & 33,4 & 51 & 18,4 & & 51 & 18,4 \\
\hline$-8 \mathrm{a}-0$ & 141 & 50,7 & 164 & 59 & Tornou-se vulnerável $(-1)$ & 44 & 15,8 \\
\hline$-16 a-8$ & 44 & 15,8 & 61 & 21,9 & Reduziu vulnerabilidade (-2) & 95 & 34,2 \\
\hline$-24 a-16$ & 0 & 0 & 2 & 0,7 & Capitalizou vulnerabilidade (-3) & 88 & 31,7 \\
\hline Total parcial & 185 & 66,5 & 227 & 81,6 & & 227 & 81,7 \\
\hline Total & 278 & 100 & 278 & 100 & & 278 & 100 \\
\hline
\end{tabular}

Apenas 2 municípios (Torre de Moncorvo e Vila Nova de Foz Coa) tornaram-se resilientes (adquiriram resiliência relativa). No primeiro caso apresentava um valor negativo em $t_{1}(-7,72)$ passando para $0,21 \mathrm{em} \mathrm{t}_{2}$. A principal razão deste resultado radica na varia- 
ção positiva (quase 44\%) que se registou no indicador e13 (taxa de variação do total de pessoal ao serviço das empresas) em $t_{2}$. Mais emprego e maior incidência da reabilitação dos edifícios estão associados ao comportamento "singular" de Vila Nova de Foz Coa.

A progressão no sentido contrário é mais frequente, na medida em que se apuraram 44 casos (cerca de 16\%) que ocupavam posições de resiliência relativa, degradando essa condição na transição entre os dois registos. Em 31,7\% dos municípios as situações de maior vulnerabilidade agravaram-se. Maior magnitude no processo de regressão pode ser identificado cruzando as posições iniciais, os valores correspondentes ao registo póscrise e a variação entre ambos (fig. 3). Por aqui se vê que em $46 \%$ dos municípios que tinham desempenhos inferiores ao nível do país antes e pós eclusão da crise, acumularam um sentido de variação negativa.

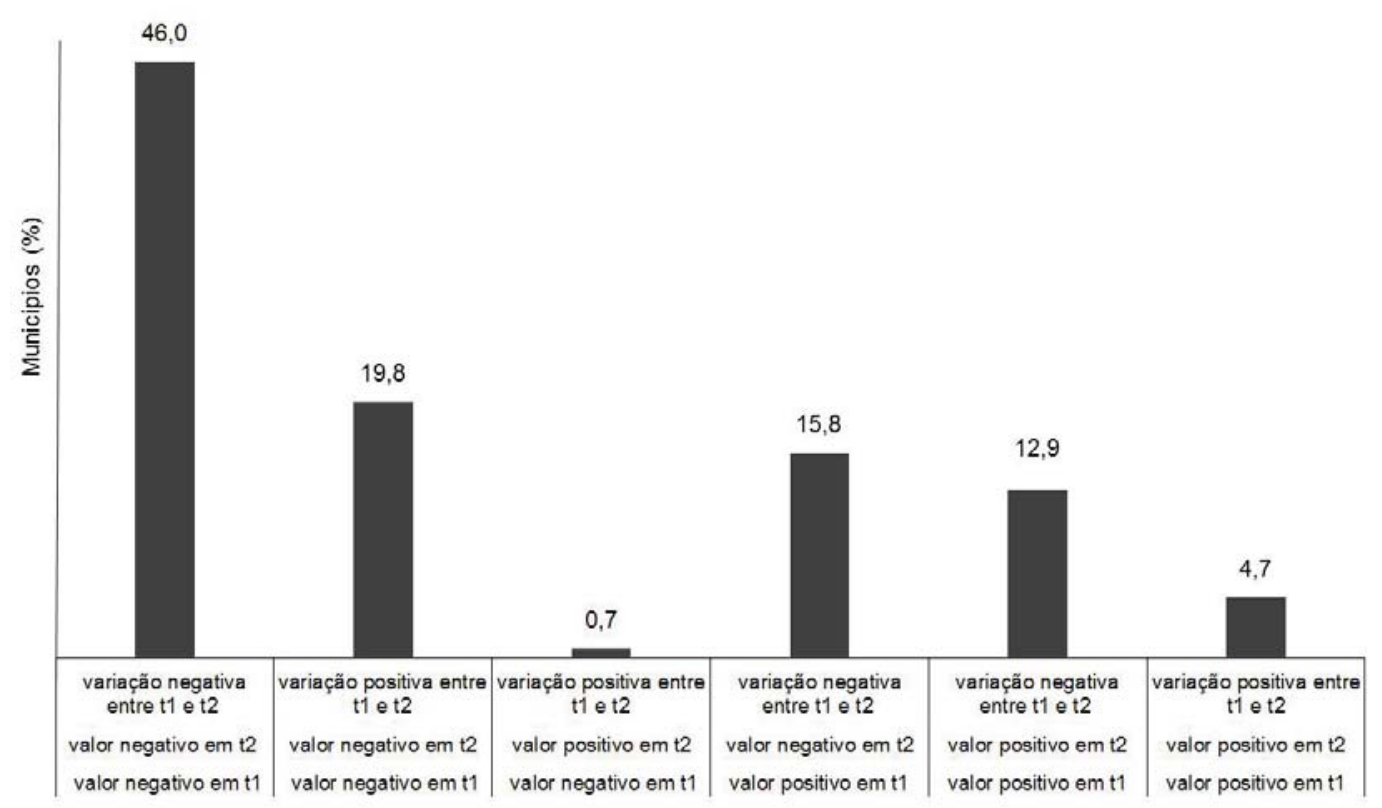

Fig. 3 - Distribuição dos municípios considerando a capacidade de resiliência em $t_{1}, t_{2}$ e evolução entre $t_{1}$ e $t_{2}$.

Fig. 3 - Distribution of the municipalities considering capacity of resilience in $t_{1}, t_{2}$ and evolution between $t_{1}$ and $t_{2}$.

Da apreciação à distribuição geográfica dos resultados, centrando a atenção na dinâmica e na tipologia que a partir dela se gerou (figs. 3 e 4), retiram-se várias ilações:

- a distribuição dos $66 \%$ de municípios que ou aprofundaram a sua vulnerabilidade ou, por efeito da retração do país no seu todo, atenuaram um pouco essas debilidades (sem contudo alterarem a sua posição de vulnerabilidade), apresenta uma mancha quase uniforme, retirando-se partes das Áreas Metropolitanas (do Porto, Lisboa e Algarve) e alguns municípios sede e distrito;

- as regiões que aprofundam a vulnerabilidade (32\% dos municípios) surgem nas margens das áreas mais dinâmicas, deixando praticamente de fora o corredor litoral e áreas do interior em torno das sedes de distrito (centros urbanos principais); 
- os 44 municípios (16\%) que transitaram para as classes de maior vulnerabilidade, localizam-se a norte (Viana do Castelo e Barcelos) e a sul (Espinho, Santa Maria da Feira, Ovar e Oliveira de Azeméis) da Área Metropolitana do Porto, a sul (Vagos) e nascente (Oliveira de Frades, Águeda, Oliveira do Bairro, Anadia e Mealhada) de Aveiro, em 6 dos 12 concelhos da NUTIII Oeste (Alcobaça, Nazaré, Caldas da Rainha, Lourinhã, Alenquer, Sobral de Monte Agraço) estendendo-se a outros municípios a nascente (Ourém, Torres Novas e Santarém). Acresce a esta lista um primeiro anel da AML-norte (Sintra, Loures e Vila Franca de Xira) e outro na AML-sul (Almada, Seixal, Moita, Sesimbra, Setúbal, Vendas Novas). No litoral alentejano Santiago do Cacém adensa este grupo. No barlavento algarvio aparece o caso de Vila do Bispo e a sotavento Olhão e Tavira. No interior, não são tão frequentes casos de municípios que se tornaram mais vulneráveis que o quadro geral do país. As exceções são: Alvito, Mourão, Alter do Chão e Castelo de Vide (no Alentejo); Figueira de Castelo de Vide (na região Centro); e, Mirandela (no nordeste Transmontano);

- os casos de municípios que, sendo mais resilientes que o cômputo do país pré2008, degradaram esta condição (6,5\%), surgem de modo mais concentrado em 9 dos 16 que compõem o Algarve (Aljezur, Lagos, Portimão, Lagos, Albufeira, Loulé, São Braz de Alportel, Faro, Vila Real de Santo António), um corredor em torno da cidade de Lisboa (Oeiras, Amadora, Odivelas), a que se juntam Benavente, Leiria e Guarda, Esposende e Maia;

- os municípios que reforçaram a sua resiliência (31 correspondendo a 11,2\%), foram Lisboa e Porto/Matosinhos e os restantes municípios com relevo no sistema urbano (Bragança, Vila Real, Aveiro/Ílhavo, Viseu, Coimbra/Condeixa-a-Nova, Castelo Branco, Portalegre, Évora, Beja, Sines). Juntam-se nesta condição alguns municípios da AML (Cascais, Mafra e Arruda dos Vinhos), Marinha Grande no centro e um núcleo a norte da AMP (Póvoa do Varzim/Vila Nova de Famalicão/Guimarães, Braga/Guimarães/Vizela/Felgueiras e Paços de Ferreira).

De modo geral assiste-se ao reforço de uma dupla polarização. Por um lado, concentra-se a capacidade de desenvolvimento nos eixos de municípios mais dinâmicos e, por outro, dentro desses corredores, reforça-se a capacidade de resiliência dos centros e aumenta a fragilidade das áreas envolventes.

Alinhando os 20 municípios que surgem nos lugares cimeiros da avaliação (quadro IV), constata-se que, no quadro geral de crise, todos reforçam a resiliência relativa, acompanhando o que anteriormente se indicou. Apenas os casos do Entroncamento, Cascais e Oeiras, regrediram um pouco na sua posição relativa. Na componente social, o menor impacto no consumo, a maior presença de formação de nível superior, a maior disponibilidade de médicos, o menor número de dependentes do Rendimento Social de Inserção (não tão visível nos casos é Faro, Lisboa, Oeiras e Porto) e os ganhos demográficos acima da média (com exceção de Coimbra, Lisboa e Porto), contribuem para este desempenho. 
O papel da diversidade social por via da presença de população estrangeira, não é tão sentido, verificando-se esta situação (considerando a dezena de concelhos) apenas em Coimbra, Lisboa e Porto.

Quadro IV - Os 20 municípios melhor e pior posicionados no Índice de Resiliência Socioeconómica Municipal.

Table IV - 20 best and worst positioned municipalities in the Municipal Socioeconomic Resilience Index.

\begin{tabular}{|c|c|c|c|c|c|c|c|}
\hline $\begin{array}{l}20 \text { concelhos melhor } \\
\text { posicionados }\end{array}$ & $\begin{array}{l}\text { Total } \\
\text { scores }\end{array}$ & $\begin{array}{c}\text { Posição } \\
\text { no } \\
\text { ranking }\end{array}$ & $\begin{array}{c}\text { Variação } \\
\text { no ranking } \\
\left(\mathrm{t}_{1}-\mathrm{t}_{2}\right) \\
\end{array}$ & $\begin{array}{l}20 \text { concelhos pior } \\
\text { posicionados }\end{array}$ & $\begin{array}{l}\text { Total } \\
\text { scores }\end{array}$ & $\begin{array}{l}\text { Posição } \\
\text { no } \\
\text { ranking }\end{array}$ & $\begin{array}{c}\text { Variação } \\
\text { no ranking } \\
\left(\mathrm{t}_{1}-\mathrm{t}_{2}\right)\end{array}$ \\
\hline Lisboa & 18,91 & 1 & 0 & Vila Nova de Paiva & $-11,57$ & 259 & 8 \\
\hline Porto & 14,60 & 2 & 1 & Mação & $-11,73$ & 260 & -49 \\
\hline São João da Madeira & 13,07 & 3 & 4 & Mora & $-11,77$ & 261 & -73 \\
\hline Coimbra & 12,30 & 4 & 0 & Chamusca & $-11,78$ & 262 & -18 \\
\hline Oeiras & 11,83 & 5 & -3 & Gavião & $-12,03$ & 263 & 12 \\
\hline Braga & 9,07 & 6 & 10 & Marco de Canaveses & $-12,28$ & 264 & -71 \\
\hline Entroncamento & 8,31 & 7 & 2 & Idanha-a-Nova & $-12,91$ & 265 & -42 \\
\hline Cascais & 8,27 & 8 & 3 & Figueiró dos Vinhos & $-13,11$ & 266 & -87 \\
\hline Aveiro & 7,44 & 9 & 9 & Penedono & $-13,39$ & 267 & 11 \\
\hline Faro & 7,33 & 10 & -4 & Tabuaço & $-13,39$ & 268 & 5 \\
\hline Albufeira & 6,49 & 11 & -6 & Boticas & $-13,61$ & 269 & -19 \\
\hline Odivelas & 5,94 & 12 & -2 & Castanheira de Pera & $-13,65$ & 270 & -13 \\
\hline Vila Real & 5,88 & 13 & 19 & Moita & $-13,77$ & 271 & -214 \\
\hline Vila Nova de Cerveira & 5,65 & 14 & 67 & Alcoutim & $-13,82$ & 272 & -21 \\
\hline Maia & 4,90 & 15 & -2 & Sabugal & $-14,30$ & 273 & -17 \\
\hline Sines & 4,79 & 16 & 70 & Penacova & $-14,71$ & 274 & -50 \\
\hline Mafra & 4,61 & 17 & 8 & Resende & $-14,96$ & 275 & -1 \\
\hline Lagos & 4,59 & 18 & -10 & Penamacor & $-14,97$ & 276 & 1 \\
\hline Amadora & 4,29 & 19 & -2 & Baião & $-18,94$ & 277 & -9 \\
\hline Portalegre & 3,85 & 20 & 13 & Cinfães & $-20,74$ & 278 & -6 \\
\hline
\end{tabular}

Pelo ponto de vista da estrutura económica, a dispersão de situações é maior. Em 6 (Cascais, Aveiro, Lisboa, Oeiras, São João da Madeira, Entroncamento) dos 20 concelhos melhor classificados aprofundou-se o quadro de resiliência face ao contexto do país. No Porto a crise degradou a condição de resiliência relativa. Os restantes três municípios tornaram-se vulneráveis na componente económica. Os primeiros beneficiaram da menor progressão (face ao que se assistiu no país) dos números do desemprego (mais no Porto, mas também em Braga, esta situação não se verifica), de maior preponderância de empresas em atividades com maior qualificação e menor dependência dos setores da construção e comércio. A redução do emprego é um dos principais fatores que constrange a capacidade de resiliência destes municípios.

Pelo lado da estrutura urbana, com exceção dos municípios de Faro e Lisboa, que atenuaram um pouco a sua capacidade de resiliência, nos restantes casos, o que se verificou foi uma capitalização da situação favorável, prévia. Reforço da concentração da população (não se aplica a Aveiro) e maior densidade demográfica influência o desempenho geral. Em 
sentido oposto, encontramos a capacidade de regeneração do edificado. A capacidade de atrair mão de obra de outros municípios (Aveiro, Cascais, Faro, Lisboa e Oeiras) e os movimentos pendulares menos perdedores de tempo e outros recursos desses territórios (Aveiro, Faro, São João da Madeira) reforçam a posição de uns e esbatem a de outros. Importa referir que todos estes casos em que, no geral, se verificou aprofundamento de resiliência, o desempenho nas variáveis de participação cívica e eleitoral vai precisamente no sentido contrário, isto é, nesta componente, acentua-se a vulnerabilidade destes municípios.

O que caracteriza os municípios pior classificados, que de um modo geral aprofundaram a sua vulnerabilidade face ao contexto do país? Têm mais dependentes na estrutura da população, perdem população, têm muito pouca ou nenhuma capacidade de fixar população estrangeira, os recursos humanos que prestam serviços de saúde são menos abundantes, a população mais qualificada escasseia e o consumo local retraiu-se mais do que a média (numa situação em que já se posicionava abaixo desta marca no período pré-crise). São municípios que mantêm a sua estrutura económica polarizada pela construção civil e pelo comércio, e a concentração da produção em torno das 4 maiores empresas acentuou-se. A redução do emprego foi mais profunda e as empresas em áreas mais qualificadas e inovadoras são raras. Junta-se a estes fatores que fragilizam a base económica, o aumento do desemprego (Alcoutim, Penamacor e Sabugal, não acompanham, tão de perto, esta regra). Não apresentam capacidade de atrair população de outros municípios (com exceção da Moita e Sabugal), o tempo das deslocações para o trabalho prolonga-se (excluindo Boticas, Castanheira de Pera, Penamacor e Sabugal), a densidade demográfica recua (excluindo o caso da Moita) e a concentração da população nos principais lugares, atenua-se. A participação em espaços de intervenção cívica é reduzida em todos. Já o défice de participação eleitoral, face ao referencial do país, só se intensifica no caso da Moita.

De modo a resumir os resultados, submetemos os valores a uma análise de clusters (figs. 5 e 6) para se extrair grupos mais homogéneos. Os critérios foram iguais para os valores dos $z_{-}$scores, devidamente normalizados, para $t_{1} \mathrm{e}_{2}$. Definiu-se que se agrupariam os concelhos em 4 clusters (testaram-se valores superiores, contudo os resultados excluíram estas hipóteses, desde logo, porque acima dos quatro surgiam grupos sem unidades de análise) e que as medidas de descriminação seriam: o vizinho mais distante com base na distância euclidiana furthest neighbor. Este método, "cria grupos muito compactos, que com dificuldade se agregam a outros, privilegiando o facto de fazer grupos tão homogéneos quanto os atributos o permitem" (Abreu, 2006, p. 217).

Se os clusters que agregam os municípios mais resilientes não sofreram alterações significativas (os clusters 3 e 4 detinham 2,9\% dos concelhos pré-crise, passando a categorizar $1,9 \%$ tendo em conta os efeitos dos 6 anos considerados), os dois que se lhe seguem, por consequência, apresentam um recuo entre o intervalo pré-2008 e os valores mais recentes (de 97,1\% para 98,6\%). Todavia, as variações mais reveladoras registam-se nos municípios inseridos nos clusters de maior fragilidade. Se em $\mathrm{t}_{1}$ o cluster 2 agregava $40 \%$ dos municípios (111), em $\mathrm{t}_{2}$ detinha $24,5 \%$ (68). $\mathrm{E}$, se em $\mathrm{t}_{1}$ o cluster de maior vulnerabilidade totalizava 158 municípios (57,2\%), em $\mathrm{t}_{2}$ caracterizava 206 municípios (74,1\%). Em resultado, a extensão de país que comporta maior vulnerabilidade, dilatou-se consideravelmente. 


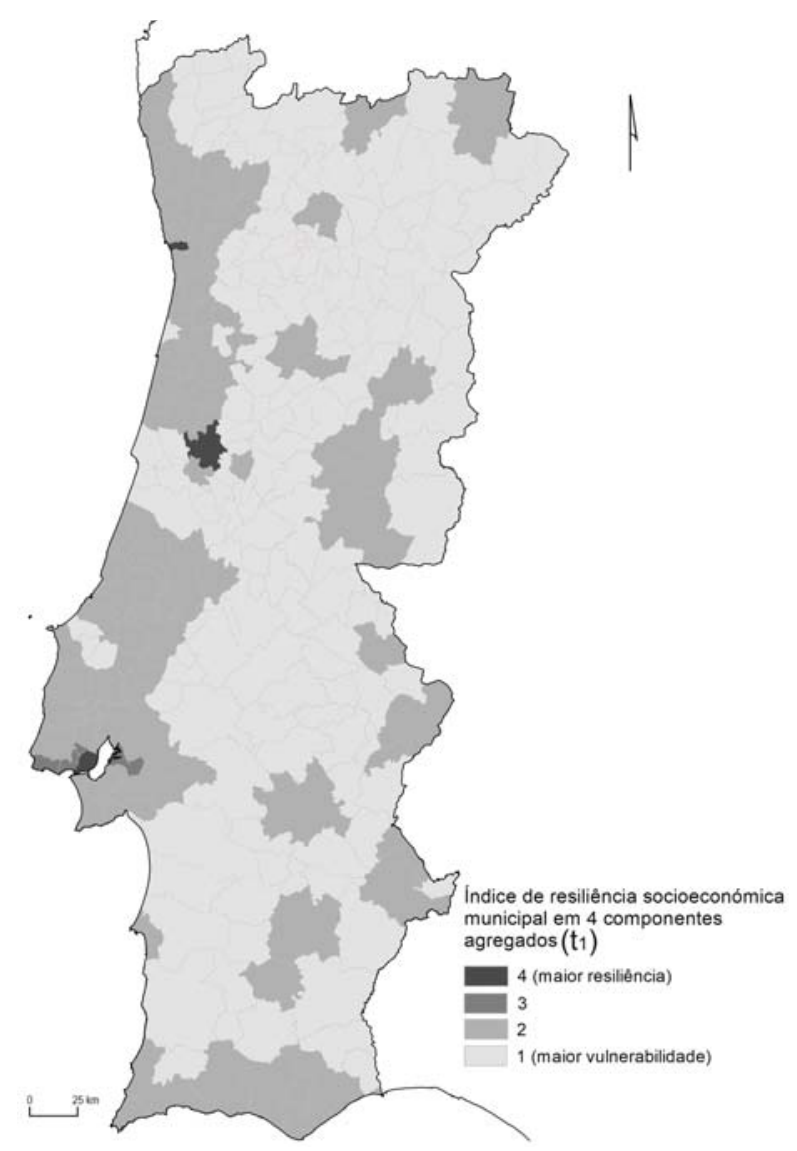

Fig. 5 - Índice de resiliência socioeconómica municipal em 4 clusters antes da crise $\left(t_{1}-2001\right.$ a 2007).

Fig. 5 - Municipal socioeconomic resilience index in 4 clusters before the crisis ( $t_{1}-2001$ to 2007).

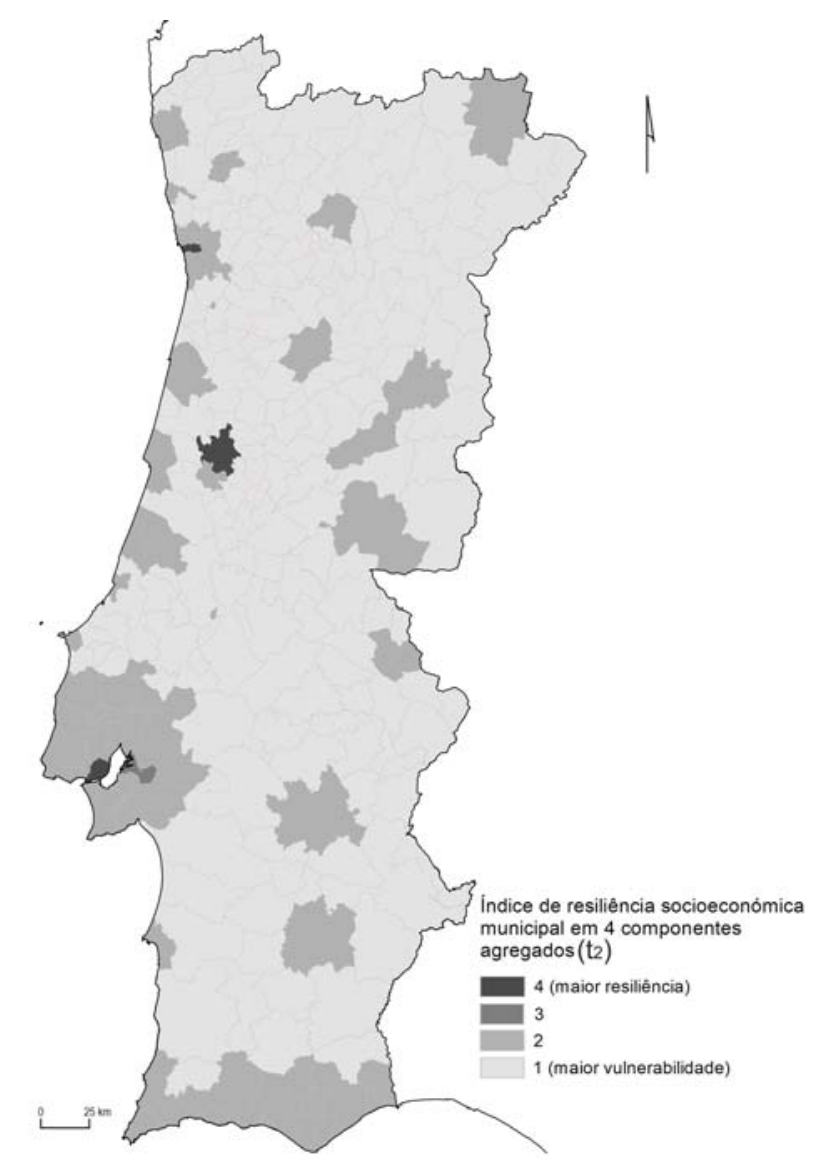

Fig. 6 - Índice de resiliência socioeconómica municipal em 4 clusters pós crise $\left(\mathrm{t}_{2}-2008\right.$ a 2013).

Fig. 6 - Municipal socioeconomic resilience index in 4 clusters post crisis ( $t_{2}-2008$ to 2013).

\section{CONCLUSÃO}

O referencial teórico da resiliência demonstra capacidade para reequacionar a consistência dos modelos de desenvolvimento, conduzindo a abordagens transversais e a avaliações integradoras de domínios e de escalas territoriais e temporais. Propõem-se formas para interpretar a distribuição desigual quer da incidência, quer dos impactos das crises.

As conclusões apresentadas corroboram os modelos de Cutter et al. (2010), cuja avaliação lhe permite afirmar que as regiões com situações mais positivas na subcomponente social são grandes ou médias áreas metropolitanas e de Naudé et al. (2009), quando afirma que maioria dos distritos com menor vulnerabilidade ou estão incluídos em áreas metropolitanas ou têm maior relação de proximidade com estas. Esta proximidade é também verificada relativamente ao estudo de Ferrão (2012) direcionado para o contexto português. A sua metodologia permite-lhe concluir que as grandes oposições territoriais (norte/sul, litoral/interior, urbano/rural) resultam esbatidas e que os principais centros urbanos manifestam maior resiliência do que os concelhos vizinhos. Estes resultados de carater mais 
generalizado incorporam também as abordagens mais centradas na dimensão económica como as Martin (2012) ou de Briguglio, Cordina, Farrugia, e Vella (2009). Retomando as questões formuladas por Meerow et al., (2016), é possível afirmar que os modelos de avaliação de resiliência territorial devem se multidimensionais, as estratégias para fomentar resiliência não se podem desviar de indicadores que traduzem variações nos quadros de vida quotidianos das famílias e que parece evidente o facto de em contextos de crise, a capacidade de resiliência (e a ausência dela) não se manifestam de forma uniforme. Os fatores que aumentam a resiliência territorial em determinados contextos (no caso estudado, os centros das áreas metropolitanas e das não metropolitanas) são favorecidos ao mesmo tempo que se induzem vulnerabilidades noutros (no caso estudado, as periferias das áreas metropolitanas e, com expressão mais ampla, as não metropolitanas).

O exercício de reunir quer os modelos quer os indicadores neles usados, permitiu-nos esmiuçar os modos e as métricas mais comummente usadas neste tipo de avaliação. Este exercício, assente em 18 estudos distintos, permitiu estabilizar quatro domínios da resiliência (social, económico, estrutura urbana e governança), dentro dos quais se organizaram os 438 indicadores utilizados nos diferentes modelos de avaliação. Os domínios mais recorrentes, a preponderância dos indicadores, a sua frequência, as fórmulas ou o sentido dos resultados foram apenas alguns dos aspetos que ressaltaram deste exercício de recolha e sistematização das métricas de avaliação da resiliência.

O índice de resiliência socioeconómica municipal decorre da síntese dos exemplos estudados e sistematizados, permitindo o afinamento dos domínios, a avaliação da sua representatividade e determinar o grupo de indicadores a incluir em cada um deles. Desta forma, estabiliza-se numa matriz de 22 indicadores (10 no domínio social, 5 no económico, 5 na estrutura urbana e 2 no da governança). $O$ índice agregado transpõe-se para uma tipologia que posiciona os diferentes territórios, atendendo à sua resiliência (permitindo apurar se capitalizou a resiliência, se reduziu resiliência ou se se tornou resiliente) ou à sua vulnerabilidade (permitindo apurar se capitalizou vulnerabilidade, se reduziu vulnerabilidade ou se se tornou vulnerável).

A matriz viabiliza várias possibilidades de análise e de representação dos resultados. Desde o tratamento isolado para cada indicador à observação conjunta para cada componente, até à verificação das indicações fornecidas pelo índice agregado. Podemos representar e analisar os resultados tendo em conta a sua variação entre $t_{1}$ e $t_{2}$, os posicionamentos das unidades de análise nos rankings para os dois períodos, o reposicionamento dos municípios nesses rankings ou ter em conta o desempenho dos territórios avaliados na tipologia apresentada.

Não obstante as limitações a que nos referimos, conclui-se que antes do início da crise, $65,5 \%$ dos concelhos ocupavam classes denunciadoras de vulnerabilidades. $\mathrm{Ou}$ seja, a estrutura que sofre os impactos da crise é na maior parte dos casos, frágil. Quando se verifica o resultado agregado dos 22 indicadores, considerando o impacto da crise, as classes de vulnerabilidade congregam $81,6 \%$ dos concelhos. Conclui-se também que 42 concelhos se deslocaram das classes de maior resiliência para as que denotam situações de vulnerabilidade. 
Tendo por referência contexto geral de crise, apenas 18,4\% dos concelhos apresentam estruturas socioeconómicas onde a capacidade de dar continuidade ao processo de desenvolvimento está menos comprometida. Por outro lado, os ganhos relativos de resiliência foram registados em apenas $11,2 \%$ dos concelhos, em contraponto às situações de aprofundamento da vulnerabilidade inicial, verificadas em $31,7 \%$ dos casos.

A distribuição espacial dos $66 \%$ de concelhos que, ou aprofundaram a sua fragilidade inicial ou, por efeito da retração geral do país atenuaram um pouco essas debilidades, sem contudo, verem alterada a sua posição de vulnerabilidade, desenha uma mancha quase uniforme, à qual se retiram partes das Áreas Metropolitanas (do Porto, Lisboa e Algarve) e alguns concelhos sede e distrito.

As regiões que aprofundam a vulnerabilidade correspondem a $32 \%$ dos concelhos, surgindo nas margens das áreas mais dinâmicas, deixando praticamente de fora o corredor litoral e áreas do interior em redor das sedes de distrito e os 6,5\% de concelhos que eram mais resilientes que o cômputo do país antes da crise, mas que degradaram esta condição, surgem de modo mais concentrado no Algarve.

Os concelhos que reforçaram a sua resiliência $(11,2 \%)$ sinalizam as polarizações de Lisboa e Porto/Matosinhos e outros nós principais do sistema urbano (Bragança, Vila Real, Aveiro/Ílhavo, Viseu, Coimbra/Condeixa-a-Nova, Castelo Branco, Portalegre, Évora, Beja, Sines). Juntam-se a estes alguns concelhos da Área Metropolitana de Lisboa (Cascais, Mafra e Arruda dos Vinhos), Marinha Grande no centro e um núcleo a norte da Área Metropolitana do Porto (Póvoa do Varzim/Vila Nova de Famalicão/Guimarães, Braga/Guimarães/Vizela/Felgueiras e Paços de Ferreira).

Analisando conjuntamente a robustez das trajetórias de desenvolvimento, conjugando fatores sociais, económicos com outros referentes à governança e, bem assim a indícios resultantes do processo de urbanização, constatamos que no decurso da fase mais aguda da crise pós-2008, o país "encolheu", expondo as fragilidades das coroas que envolvem os eixos de municípios mais dinâmicos (o centro das Áreas Metropolitanas e os aglomerados urbanos principais no espaço não metropolitano). Exibiram-se, nesta fase, as fragilidades das políticas públicas tanto as que orientaram por ação ou por inação a expansão das Áreas Metropolitanas, como as que suprimiram diversidade, capacidade de redundância, adaptabilidade, transformabilidade e cultura de participação em quase todo o país não metropolitano.

Perante um quadro de crise severa, expuseram-se décadas de políticas públicas assentes em princípios de crescimento e expansão no caso das Áreas Metropolitanas e de uma sucessão de intervenções destinadas a uniformizar o país não metropolitano. Todavia, as conclusões desta análise apontam no sentido de que, num contexto de crise como a que teve lugar pós-2008, boa parte dos concelhos afastados dos centros das metrópoles e o restante território que envolve os poucos nós polarizadores no espaço não metropolitano manifestam sinais de fragilidade.

Esta vulnerabilidade decorre do efeito cumulativo de fragilidades sociais (nas estrutura de qualificações, no afastamento face a serviços e a centros geradores de emprego, na maior dificuldade de aceder a fontes de rendimentos transposto em baixo poder de com- 
pra, que, em certa parte, se encontra capturada pelos compromissos que as famílias assumiram com a aquisição de habitação própria), económicas (deficitárias em diversidade, fazendo depender a oferta de emprego de um grupo restrito de empresas integradas em setores tais como, construção e comércio por grosso), da estrutura urbana (fragmentada, dispersa e assente em baixas densidades, alavancada pelo processo de construção/urbanização e com pouca capacidade de gerar renovação e transformações de usos, provocando ininterruptos alargamentos nas bacias de emprego e gerando pouca capacidade de criar novos nós atractores de fluxos ou de consolidar os pré-existentes) e dos dispositivos de governação (comunidades pouco aptas a desenvolver instrumentos e competências para interferir nos processos de decisão).

De modo a contrapor este efeito e a preparar o país para outros episódios disruptivos, impõe-se discutir a natureza da cidade criada nas coroas externas das Áreas Metropolitanas porque este crescimento parece estar assente em fatores que em situações de crise reforçam a polarização das áreas centrais. Por outro lado, as políticas ditas pró-coesão e pró-desconcentração direcionadas para o vasto território não metropolitano manifestam pouca consistência, redundando, também, na sedimentação da polarização do capital de desenvolvimento num número reduzido de centros urbanos.

Este exercício permite retirar conclusões quanto à forma como os municípios de Portugal Continental responderam aos 6 anos da crise pós-2008, demonstrando que num contexto de crise severa, o potencial de desenvolvimento tende a concentrar-se nas áreas centrais dos centros urbanos mais dinâmicos, configurando um reforço do processo de dupla polarização. A incorporação dos princípios da resiliência evolutiva nos instrumentos de planeamento e nos dispositivos de governação territorial, conjugando o seu potencial analítico com a capacidade de formular propostas diferenciadas, podem contribuir para preparar o país para situações de tensão, crise e rutura, criando modelos de desenvolvimento metropolitano e não metropolitano mais resilientes. Isto é, aptos a sustentar progresso continuado gerador de incrementos de qualidade de vida, mesmo em período de incerteza e/ou de crise.

\section{AGRADECIMENTOS}

Este artigo resulta do projeto de investigação desenvolvido no âmbito de uma bolsa de Doutoramento (referência SFRH/BD/66158/2009) financiada pela Fundação para a Ciência e a Tecnologia. 


\section{REFERÊNCIAS BIBLIOGRÁFICAS}

Abreu, D. (2006). Análise Multivariada de Informação Geográfica [Multivariate Analysis of Geographic Information]. Lisboa: Centro de Estudos Geográficos, Universidade de Lisboa.

Adger, N. W. (2000). Social and ecological resilience: are they related? Progress in Human Geography, 24(3), 347-364. doi: 10.1191/030913200701540465

Beilin, R., \& Wilkinson, C. (2015). Introduction: Governing for Urban Resilience. Urban Studies, 52(7), 1205-1217. doi: 10.1177/0042098015574955

Boschma, R. (2014). Towards an Evolutionary Perspective on Regional Resilience. Regional Studies, 49(5), 1-19. doi: 10.1080/00343404.2014.959481

Boschma, R., \& Martin, R. (2007). Constructing an evolutionary economic geography. Journal of Economic Geography, 7(5), 537-548. doi: 10.1093/jeg/ lbm021

Briguglio, L., Cordina, G., Farrugia, N., \& Vella, S. (2009). Economic Vulnerability and Resilience: Concepts and Measurements. Oxford Development Studies, 37(3), 229-247. doi: 10.1080/13600810903089893

Cachinho, H. (2012). Consumerscapes and the resilience assessment of urban retail systems. Cities, 36. doi: 10.1016/j.cities.2012.10.005

Chapple, K., \& Lesterb, T. W. (2010). The resilient regional labour market? The US case. Cambridge Journal of Regions, Economy and Society, 3, 85-104. doi: /10.1093/cjres/rsp031

Chmutina, K., Lizarralde, G., Dainty, A., \& Bosher, L. (2016). Unpacking resilience policy discourse. Cities, 58, 70-79. doi: 10.1016/j.cities.2016.05.017

Cutter, S., Barnes, L., Berry, M., Burton, C., Evans, E., Tate, E... Webb, J. (2008). Community and regional resilience: perspectives from hazards, disasters, and emergency management. CARRY Research Report 1. South Carolina, Columbia: Community and Regional Resilience Initiative.

Cutter, S., Boruff, B., \& Shirley, L. (2003). Social Vulnerability to Environmental Hazards. Social Science Quarterly, 84(2), 242-261.

Cutter, S. L., Burton, C. G., \& Emrich, C. T. (2010). Disaster Resilience Indicators for Benchmarking Baseline Conditions. Journal of Homeland Security and Emergency Management, 7(1), 1-21.

Davoudi, S. (2012). Resilience: A Bridging Concept or a Dead End? Planning Theory \& Practice, 13(2), 299-333. doi: 10.1080/14649357.2012.677124
ESPON. (2013). Economic Crisis and the Resilience of Regions. Territorial Observation No. 12, Luxembourg: ESPON, European Union.

European Commission Directorate-General for Economic and Financial Affairs. (2009). Economic Crisis in Europe: Causes, Consequences and Responses. European Economy 7. Luxembourg: European Commission Directorate-General for Economic and Financial Affairs.

Fernandes, J., \& Chamusca, P. (2012). Urban policies, planning and retail resilience. Cities, 36, 170-177. doi: 10.1016/j.cities.2012.11.006

Ferrão, J. (2012). A geografia da crise [The geography of the crisis]. Conferências ICS 2012 "Portugal em Mudança: diversidade, assimetrias $e$ contrastes" [Portugal in Change: diversity, asymmetries and contrasts] (p. 17). Lisboa: Instituto de Ciências Sociais da Universidade de Lisboa.

Foster, K. A. (2007). Snapping Back What Makes Regions Resilient? National Civic Review, 96(3), 27-29. doi: $10.1002 / \mathrm{ncr}$

Foster, K. A. (2006). A Case Study Approach to Understanding Regional Resilience. In Annual Conference of the Association of Collegiate Schools of Planning (pp. 1-45). Fort Worth, Texas: Institute of Urban and Regional Development.

Giannakis, E., \& Bruggeman, A. (2015). Economic crisis and regional resilience: Evidence from Greece. Papers in Regional Science, (April). doi: 10.1111/ pirs.12206

Homer-Dixon, T., Walker, B., Biggs, R., Crépin, A. S., Folke, C., Lambin, E. F... Troell, M. (2015). Synchronous failure: The emerging causal architecture of global crisis. Ecology and Society, 20(3), 6. doi: 10.5751/ES-07681-200306

Hung, H. C., Yang, C. Y., Chien, C. Y., \& Liu, Y. C. (2016). Building resilience: Mainstreaming community participation into integrated assessment of resilience to climatic hazards in metropolitan land use management. Land Use Policy, 50, 48-58. doi: 10.1016/j.landusepol.2015.08.029

Instituto Nacional de Estatística. (INE). (2013). Censos 2011 [Census 2011]. Retrived from http://censos.ine.pt/xportal/xmain?xpgid=censos 2011 apresentacao\&xpid=CENSOS 
Instituto Nacional de Estatística. (INE). (2002). Censos 2001 [Census 2011]. Retrived from http://censos.ine.pt/xportal/xmain?xpid=INE\&xpgid= censos historia pt

Martin, R., Sunley, P., Gardiner, B., \& Tyler, P. (2016). How Regions React to Recessions: Resilience and the Role of Economic Structure. Regional Studies, 50(4), 561-585. doi: 10.1080/00343404.2015.1136410

Martin, R. (2012). Regional economic resilience, hysteresis and recessionary shocks. Journal of Economic Geography, 12(1), 1-32. doi: 10.1093/jeg/ lbr019

Martin, R., \& Sunley, P. (2003). Complexity Thinking and Evolutionary Economic Geography. (Papers in Evolutionary Economic Geography No. 07.03). Utrecht. Retrieved from http://econ.geog.uu.nl/ peeg/peeg.html

Meerow, S., Newell, J. P., \& Stults, M. (2016). Defining urban resilience: A review. Landscape and Urban Planning, 147, 38-49. doi: 10.1016/j.landurbplan.2015.11.011

Naudé, W., McGillivray, M., \& Rossouw, S. (2009). Measuring the Vulnerability of Subnational Regions in South Africa. Oxford Development Studies, 37(3), 249-276. doi: 10.1080/13600810903085800

Pendall, R., Foster, K. A., \& Cowell, M. (2009). Resilience and regions: building understanding of the metaphor. Cambridge Journal of Regions, Economy and Society, 3(1), 71-84. doi: 10.1093/cjres/ rsp028

Pinho, P., Oliveira, V., Cruz, S. S., Sousa, S., Martins, A., Morgado, S... Dias, L. (2008). SUPERCITIES -Sustainable Land Use Policies for Resilient Cities. Final Report. Porto: Faculdade de Letras, Universidade do Porto

Pu, B., \& Qiu, Y. (2016). Emerging trends and new developments on urban resilience: A bibliometric perspective. Current Urban Studies, 4, 36-52.
Barata Salgueiro, T., Cachinho, H. (2011). Retail Planning for the Resilient City, Consumption and Urban Regeneration. Lisboa: Centro de Estudos Geográficos, Universidade de Lisboa.

Sensier, M., Bristow, G., Healy, A., \& Kiel, C. (2016). Measuring Regional Economic Resilience across Europe: Operationalizing a complex concept. Spatial Economic Analysis, 11(2), 128-151. doi: 10.1080/17421772.2016.1129435

Simmie, J., \& Martin, R. (2010). The economic resilience of regions: towards an evolutionary approach. Cambridge Journal of Regions, Economy and Society, 3(1), 27-43. doi: 10.1093/cjres/rsp029

Sousa, S. Á. de. (2010). Planning for Shrinking Cities in Portugal. Porto: Universidade do Porto.

Suárez, M., Gómez-Baggethun, E., Benayas, J., \& Tilbury, D. (2016). Towards an Urban Resilience Index: A Case Study in 50 Spanish Cities. Sustainability, 8(8), 774. doi: 10.3390/su8080774

Teigão dos Santos, F., \& Partidário, M. R. (2011). SPARK: Strategic Planning Approach for Resilience Keeping. European Planning Studies, 19(8), 1517-1536. doi: 10.1080/09654313.2011.533515

Wilkinson, C. (2012). Social-ecological resilience and planning: an interdisciplinary exploration. Stockholm: Stockholm University.

Wolleb, G., \& Daraio, A. (2009). Regional Challenges in the Perspective of 2020 - regional disparities and future challenges. A report to the Directorate-General for Regional Policy Unit Conception, forward studies, impact assessment. ISMERI EUROPA.

Wolman, H. L., Ford, C. C., \& Hill, E. (1994). Evaluating the success of urban success stories. Urban Studies, 31(6), 835-850.

Xu, L., \& Marinova, D. (2013). Resilience thinking: a bibliometric analysis of socio-ecological research. Scientometrics, 96(3), 911-927. doi: 10.1007/s111 92-013-0957-0 